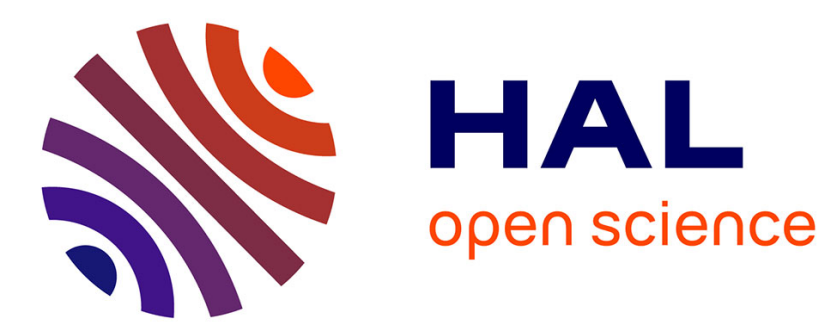

\title{
La peste nord-africaine et la théorie de Charles Nicolle sur les maladies infectieuses
}

Néfissa Kmar Ben, Anne Marie Moulin

\section{To cite this version:}

Néfissa Kmar Ben, Anne Marie Moulin. La peste nord-africaine et la théorie de Charles Nicolle sur les maladies infectieuses. Gesnerus, 2010, 67 (1), pp.30-56. 10.24894/Gesn-fr.2010.67003 . pasteur00613045

\section{HAL Id: pasteur-00613045 https://hal-riip.archives-ouvertes.fr/pasteur-00613045}

Submitted on 2 Aug 2011

HAL is a multi-disciplinary open access archive for the deposit and dissemination of scientific research documents, whether they are published or not. The documents may come from teaching and research institutions in France or abroad, or from public or private research centers.
L'archive ouverte pluridisciplinaire HAL, est destinée au dépôt et à la diffusion de documents scientifiques de niveau recherche, publiés ou non, émanant des établissements d'enseignement et de recherche français ou étrangers, des laboratoires publics ou privés. 


\section{La peste nord-africaine et la théorie de Charles Nicolle sur les maladies infectieuses*}

Kmar Ben Néfissa et Anne Marie Moulin

\section{Summary}

Many infectious diseases were described in North Africa in 18th-19th centuries by European travellers. Most of them were allegedly imported by new migrant populations coming from sub-Saharan, European or Middle East countries. Plague outbreaks have been described since the Black Death as diseases of the Mediterranean harbours. Charles Nicolle and his collaborators at the Pasteur Institute were witnesses to the extinction of plague and typhus fever in Tunisia. Both could be considered as endemo-epidemic diseases propagated by ancient nomad communities for centuries. Typhus was exported to other countries; plague was imported by Mediterranean travellers but also hid in unknown wild-animal reservoirs. The role of the bite of a rat's flea was not confirmed and the pneumonic form might have prevailed in the medieval North African cities. Association between plague, typhus, flu and other causes of immune deficiencies could explain the high morbidity and mortality caused by plague in the past. The authors comment the local history of plague at the light of the evolutionary laws of infectious disease proposed by Charles Nicolle in 1930 .

Keywords: plague; typhus fever; North Africa; host pathogen relations; Evolution; Charles Nicolle

* Les auteures remercient Koussay Dellagi et Maurice Huet pour leur collaboration à la préparation de cet article.

Kmar Ben Néfissa, Institut Pasteur de Tunis, B.P. 74, Le Belvédère, TUN-1002 Tunis (kmar. bennefissa@ pasteur.rns.tn).

Anne Marie Moulin, CNRS, SPHERE, UMR 7219, Université de Paris 7 (anne.saintromain@ gmail.com). 


\section{Résumé}

De nombreuses maladies infectieuses ont été décrites en Afrique du Nord aux XVIII ${ }^{\mathrm{e}}$ et $\mathrm{XIX}^{\mathrm{e}}$ siècles par des voyageurs européens. La plupart d'entre elles, soupçonnait-on, étaient importées par les nouvelles populations migrantes venues des pays sub-sahariens, d'Europe ou d'Asie. Au début du $\mathrm{XX}^{\mathrm{e}}$ siècle, Charles Nicolle et ses collaborateurs ont assisté à l'extinction de la peste et du typhus exanthématique au nord de l'Afrique. Il ressort de leurs observations de nouvelles hypothèses sur l'origine, l'évolution et les modalités de transmission locale de la peste: celle d'ancêtres nomades réservoirs et propagateurs de maladies très anciennes contrastant avec des maladies nouvelles importées par les vagues de migrations successives, celle de la prédominance des formes pulmonaires dans les épidémies urbaines, celle de l'association de la peste avec la grippe, le typhus et autres causes de déficits immunitaires collectifs expliquant la morbidité et la mortalité spécifique exceptionnelle observées certaines années dans certaines villes. Les idées qu'on peut dire évolutionnistes sur le destin des maladies infectieuses, proposées par Charles Nicolle en 1930, ont été à la fois l'aboutissement et la trame des recherches pasteuriennes en Afrique du Nord.

\section{Introduction}

Malgré les puissants moyens de diagnostic rétrospectif et de pronostic que possède aujourd'hui la médecine, il subsiste de nombreuses questions sur le cycle naturel des infections. Pour la peste par exemple, comment expliquer son impact disproportionné dans l'histoire humaine alors que le micro-événement à l'origine de la contamination, c'est-à-dire la rencontre entre l'homme et le bacille, est un événement théoriquement peu probable? ${ }^{1}$ Connue sous le terme de ta'un chez les Arabes ${ }^{2}$, la peste fut longtemps considérée comme une maladie du mécréant ou bien comme une épreuve divine, par une majorité de toute façon réticente à des mesures de prophylaxie ${ }^{3}$. Elle

1 Le mécanisme par lequel la puce de rat transmet le bacille de la peste par sa piqûre a été décrit tout en étant admis comme peu efficace. Ce mécanisme de transmission ne peut à lui seul expliquer la surmortalité des pestes médiévales: Audouin-Rouzeau 2003.

2 Ta'un n'est pas une transcription du syriaque sharuta ni du grec boubôn. On note son homonymie, en arabe, avec ta'un, ou épée. Ce n'est sans doute pas un hasard lexicographique. Dans les dialectes berbères locaux, la peste était aussi désignée par d'autres termes tels que boukebar, boutabeg.

3 Les Arabes ont mis tout leur soin à distinguer la peste des autres maladies épidémiques, désignées par des termes spécifiques ou par le terme général de waba (qui recouvre toutes les 
aurait provoqué plusieurs vagues de dépeuplement en Afrique du Nord, où l'épidémie de 1785 à 1820 aurait emporté la moitié de la population avec des pics de mortalité supérieurs à 1000 décès journaliers contre moins de 10 les jours ordinaires dans des cités dont la population ne dépassait pas cent à deux cents mille habitants ${ }^{4}$. Cette surmortalité est-elle est due à la peste? A-t-elle une (ou des) explication(s)?

Il nous a paru intéressant de nous référer à un témoin de l'extinction de la peste en Tunisie, Charles Nicolle (1866-1936), directeur de l'Institut Pasteur de Tunis (1902-1936) et prix Nobel pour ses recherches sur le typhus en 1928. Les microbes et les infections ont été au centre de sa vie et de son œuvre et il a connu la peste à une période charnière entre l'ère pré- et post-bactériologique, post-darwinienne et pré-génomique et dans une région également charnière entre l'Europe, l'Afrique et le Moyen Orient. Charles Nicolle a développé en 1930 ce qui peut être compris comme une théorie évolutionniste de l'infection, c'est-à-dire un système explicatif qui intègre le fait qu'il y a une histoire des microorganismes vivants ${ }^{5}$. Ses hypothèses paraissaient évidemment largement spéculatives à une époque où seul un petit nombre de microbes étaient encore connus, mais beaucoup d'entre elles ont retrouvé une actualité avec les maladies émergentes, en particulier avec le SIDA. Nicolle avait prédit avec assurance l'apparition de nouvelles infections, la fin de la variole, l'extension des «maladies d'avenir» et la persistance du phénomène infectieux, quelle qu'en fût la forme, dans les temps à venir' ${ }^{6}$. La place de la peste dans son œuvre scientifique est pourtant a priori mineure: à peine quatre publications sur plus de cinq cents. Mais la maladie est loin d'être absente de ses préoccupations. Nicolle l'évoque de ci, de là, souvent en relation avec d'autres infections et en particulier avec son modèle favori, le typhus ${ }^{7}$.

causes de mortalité et de morbidité collective: contagion, corruption de l'air et de l'environnement). Le ta'un a toujours eu un statut particulier chez les musulmans du fait que la peste justinienne a été contemporaine de l'hégire et de l'épopée du premier djihad en Syrie et en Irak. Au moment de la peste noire et des épidémies qui ont suivi et alors que les sciences médicales arabes étaient à leur apogée, les juristes ont discuté de l'origine de la peste et de l'attitude du croyant face à elle. Les arguments, contradictoires, étaient tirés de la chari'a mais aussi d'observations venant des sciences profanes, pour savoir si elle était contagieuse ou divine. Mise à part l'intime conviction de médecins célèbres d'Andalousie (Ibn Khatib et Ibn Khatima, 1348), le caractère aléatoire de la transmission de la peste a fait souvent rejeter l'hypothèse de sa contagiosité. La peste a fini par acquérir une dimension de maladie héroïque et ses victimes étaient plus ou moins considérées comme des chahid, martyrs. Les hagiographes la mentionnent dans les causes de décès des gens célèbres: Sublet 1971; Dols 1977; Conrad 1981; Saadaoui 1995.

4 Marchika 1927; Bloch 1929; Sebag 1965.

5 Nicolle 1937.

6 Nicolle 1935a; Nicolle 1935b; Nicolle 1935c.

7 Le typhus exanthématique est une maladie à réservoir humain transmise par les poux de corps. Il appartient au groupe des typhus, dû à de très petits bacilles du genre Rickettsia. 
La peste est une maladie du rongeur transmise à l'homme par sa puce et due à un bacille très virulent, Yersinia pestis. Les médecins aujourd'hui admettent trois formes cliniques (bubonique, pulmonaire et septicémique) et deux cycles épidémiologiques distincts: un cycle à transmission vectorielle par la puce de rongeur et un cycle à transmission directe par voie aérogène. Dans ses foyers naturels, le bacille survit dans des biotopes particuliers, grâce à des épisodes alternés chez des espèces de rongeurs sensibles qui infectent les puces et chez des espèces de rongeurs résistants qui disséminent le bacille présent chez les puces, dans leurs déjections et le sol des terriers. L'homme se contamine suite à un contact accidentel avec un animal sauvage infecté (maladie du chasseur de fourrures) ou bien à une épizootie chez le rat domestique. Il y eut trois pandémies de peste dans le Vieux Monde moissonnant chacune des millions de victimes: la peste justinienne (650), la peste noire (1347) et la peste de Hong Kong (1894). Cette étude se propose de présenter les contributions de l'école pasteurienne d'Afrique du Nord à nos connaissances sur la peste et de commenter quelques hypothèses sur l'histoire naturelle de cette maladie à travers la comparaison avec le typhus exanthématique, autre maladie locorégionale longtemps confondue mais de destin parallèle, y compris pour l'histoire scientifique: la plupart des auteurs d'Afrique du Nord ayant traité de la peste ont aussi traité du typhus.

\section{Charles Nicolle, la peste et le typhus}

\section{Les débuts de l'ère scientifique de la peste: peste et ta'un}

Tous les médecins passés par l'Ecole ont eu à connaître la peste, ou plutôt sa représentation, dans leur formation scientifique depuis le Moyen Age. Charles Nicolle entama des études de médecine, après avoir penché pour la littérature et l'histoire, dans les années qui suivirent immédiatement l'émergence de la nouvelle doctrine scientifique des infections avec ses chefs de file, Louis Pasteur en France et Robert Koch en Allemagne. Beaucoup de jeunes savants de l'époque, sans doute, ont caressé le rêve de résoudre les énigmes de cette maladie légendaire, celle-là même qui tourmentait depuis des siècles académiciens, diplomates, hommes de religion, Orient et Occident. En 1894, Alexandre Yersin identifie l'agent causal, baptisé Bacterium pestis, à Hong Kong et prouve l'unité de la maladie chez l'homme et le rat ${ }^{8}$. Paul Louis

8 Le japonais Shibasaburo Kitasato aurait identifié le bacille plus tôt, mais aurait décrit imparfaitement ses caractéristiques tinctoriales: voir Zietz/Dunkelberg 2004. 
Simond, trois années plus tard, propose un modèle de transmission avec la puce de rat comme vecteur. Ces découvertes pasteuriennes majeures sont à l'origine d'une cascade d'événements dans le monde scientifique et dans la société. Les pasteuriens, à juste titre, fêtent cette victoire de la science comme étant la leur. Une série de conférences sur l'actualité de la peste est organisée. Emile Roux, directeur du prestigieux Institut Pasteur de Paris, se déplace en personne à Rouen où le jeune médecin et biologiste Charles Nicolle, qui y travaille entre 1898 et 1902, tente, sans grand succès, de faire admettre les nouvelles conceptions pasteuriennes et les nouveaux procédés de sérodiagnostic et séroprophylaxie dans sa Normandie natale, patrie de Pouchet, contradicteur de Pasteur à propos de la question des «générations spontanées»?.

A Tunis, un certain Paul Remlinger, jeune médecin militaire, réunit ses confrères pour une conférence sur la peste ${ }^{10}$. Un nouveau paradigme vient de naître avec, à la clef, les bases d'une prophylaxie scientifique: la lutte contre le rat. Ces découvertes mettent définitivement un terme au débat contagionniste (proquarantenaire) et anticontagionniste (antiquarantenaire) non seulement en Europe mais aussi dans le monde arabo-musulman ${ }^{11}$. En Tunisie, dès le XVIII ${ }^{\mathrm{e}}$ siècle, malgré l'opposition d'une majorité des courants religieux contre ces «pratiques chrétiennes», les beys successifs tentent d'imiter le modèle occidental des quarantaines ${ }^{12}$. Ces mesures de prophylaxie collective seront inapplicables du fait du nombre annuel de plus en plus important de pèlerins optant pour le transport maritime vers le Hijjaz. L'incapacité manifeste du dispositif quarantenaire à contenir la propagation de la pandémie de choléra de 1830 a aussi nourri les doutes sur la contagion. La découverte de la cause de la peste aurait contribué à venir à bout des réticences religieuses, car, en février 1896 à Alger, les jurisconsultes musulmans des différentes écoles se sont réunis pour déclarer unanimement: oui, l'usage des procédés prophylactiques contre la peste est recommandé aux croyants; non, le recours à la médecine européenne n'est pas illicite ${ }^{13}$.

Le bacille de la peste à peine identifié est l'objet d'une surveillance épidémiologique étroite:il se propage rapidement de port en port, atteint le bassin méditerranéen (Marseille, Alger,1898) et est signalé pour la première fois dans le Nouveau Monde en 1900. Des savants de diverses nationalités, dissé-

9 Debré 1994; Salomon-Bayet 1986: voir en particulier dans ce dernier ouvrage la contribution de Bruno Latour, «Au théâtre des preuves», 337-384.

10 Remlinger 1899.

11 Proust 1897; Sublet 1971; Gallagher 1983; Panzac 1986; Moulin 1996.

12 Gallagher 1983, Archives du Gouvernement de Tunis, dossiers 801 à 807 (Série Historique).

13 La médecine et les quarantaines dans leurs rapports avec la loi musulmane, Alger, 1896. 
minés dans les quatre continents, découvrent sa vitalité dans des conditions de laboratoire habituellement hostiles aux agents pathogènes et sa virulence vis-à-vis d'un spectre élargi d'espèces mammifères ${ }^{14}$. La Commission anglaise des Indes sur la peste, créée en 1905, et longtemps référence des recherches sur la maladie, butait néanmoins sur des questions insolubles quant aux mécanismes précis de contamination par la puce, au mode de conservation du bacille pendant les périodes interépidémiques dans différentes régions du globe, à la manière dont il se propage chez l'homme et le rongeur puis arrête brusquement sa progression. Les recherches expérimentales et les diverses observations ne parvenaient pas à s'accorder sur un modèle universel qui explique, par exemple, la persistance de la peste en Angleterre et aux Indes ${ }^{15}$. Un principe de spécificité locorégionale fut tacitement admis: à chacun sa peste ${ }^{16}$.

On a quelques raisons de croire que la peste apparait très tôt dans les préoccupations de Charles Nicolle alors qu'il est loin des remous provoqués par la troisième pandémie ${ }^{17}$. Tandis que son frère Maurice, brillant pasteurien de la première génération, est en poste à Constantinople au centre du conflit politico-sanitaire entre l'Orient et l'Occident, Charles Nicolle publie entre 1898 et 1901 quatre articles en rapport avec la «peste d'Orient» dans des revues normandes: l'un sur les produits d'hygiène turcs et deux consacrés à la biographie de deux médecins rouennais qui ont vécu en terre d'Islam, le Dr René-Nicolas Desgenettes, médecin de la campagne napoléonienne en Egypte, témoin de l'épidémie de «peste» de Jaffa et le Dr Frédéric Borel, membre de l'administration sanitaire ottomane, témoin et acteur des épidémies de «peste» de 1897, 1898, 1899 et 1900 au Hijjaz. Charles Nicolle y fait une distinction entre le foyer endémique de la région d'Assyr et le foyer d'importation de Djeddah, port de débarquement des pèlerins.

On peut dire que c'est par l'étude de la peste que Charles Nicolle prend connaissance du monde musulman et de ses coutumes. Il le rejoint le 23 décembre 1902 pour prendre la direction de l'Institut Pasteur de Tunis ${ }^{18}$.

14 Voir par exemple Eager 1908 et Rosenau 1901.

15 Revue d'Hygiène et de Police Sanitaire 4 (1924) 358-365.

16 Pollitzer 1954.

17 Proust 1897; Moulin 1992.

18 L'Institut Pasteur de Tunis fut fondé en 1893, à l'initiative de Louis Pasteur, par son neveu, Adrien Loir. Centre de vinification auquel fut rajouté un centre vaccinogène et antirabique en 1894, il était situé dans un petit local du centre ville. Avec les nouveaux bâtiments construits en 1904, Charles Nicolle introduisit de nouvelles activités (animalerie, bactériologie, production de sérums et vaccins, bibliothèque) et de nouvelles unités de recherches. Son statut était unique dans le réseau pasteurien puisqu'il dépendait du gouvernement tunisien et non de la maison mère ou Rue Dutot, ce qui permit aux pasteuriens de Tunis de jouir d'une relative autonomie scientifique: Moulin 1994; Pelis 2006. 
Il découvre la foule bigarrée d'une capitale orientale où de nombreuses communautés cohabitent séparément avec chacune ses origines, ses espaces, ses coutumes et ses croyances. Il part à Djerba chasser le microbe et croise l'autre Tunisie, celle du bled, des paysages arides, des caravanes nomades et des pasteurs. Il collecte divers spécimens de la flore et de la faune, examine les produits de ses prélèvements au microscope et rédige des comptes rendus aux académies où percent ses penchants naturalistes ${ }^{19}$. Du fait d'une surdité et d'un déficit visuel très probable qui lui faisait confondre certaines couleurs, le savant vivra très proche de ses collaborateurs. Pour chaque système infectieux, il s'associera un ou plusieurs chercheurs: pour le typhus, Ernest Conseil, Charles Comte et plus tard Helena Sparrow et Charles Anderson; pour la peste, Ernest Conseil, Ernest Gobert et plus tard Paul Durand et Georges Blanc au Maroc; pour la brucellose, la rage, le trachome, les spirochétoses, il y aura Etienne Burnet, Etienne Balozet, Auguste Jean Cuénod et Charles Anderson et d'autres encore, sans compter ses collaborateurs parisiens tel que le syphiligraphe Emile Leredde ou internationaux du groupe de recherche sur le typhus ${ }^{20}$.

\section{Les trois visages de la peste nord-africaine}

Dès son arrivée, Charles Nicolle se renseigne autour de lui sur la peste et il fait remonter la dernière épidémie grave à 1837 , la localisant précisément à Djerba. Il lui faudra attendre 5 ans pour enfin voir en 1907 ses premiers cas cliniques groupés à l'occasion d'un petit foyer portuaire à Tunis (importé de Marseille) qui fut vite éteint. Dès lors, les recherches sur la maladie s'intensifient: création d'un laboratoire de surveillance des rats dans le port de Tunis, première enquête sur les rongeurs et leurs ectoparasites par Ernest Conseil qui dirige désormais un service anti-pesteux à l'Institut Pasteur de Tunis, alors qu'il vient d'achever sa thèse sur le typhus exanthématique. Tout en guettant un foyer humain de typhus pour tenter une reproduction expérimentale de la maladie sur un singe de type bonnet chinois, les deux savants passent le nouvel intrus, rebaptisé entre temps Bacillus pestis, au tamis de la médecine expérimentale sur le cobaye. Les cobayes, très sensibles à la peste, sont utili-

19 Dès 1903, Charles Nicolle relève les variations morphologiques d'un microorganisme, l'hémogrégarine, en fonction de différentes espèces d'hôte, et les «relations étranges» entre les débris de globules rouges éclatées et le parasite qui leur reste accolé: voir Comptes-Rendus de la Société de Biologie (1904) 330, 608 et 912.

20 Lot 1961; Huet 1995. On note qu'Edouard Chatton, initiateur d'André Lwoff, un des pères de la biologie moleculaire, a sejourné en Tunisie entre 1913 et 1918 et a même occupé un poste de sous directeur de Laboratoire à l'Institut Pasteur de Tunis entre 1916 et 1918. 
sés pour le diagnostic rapide de la maladie. Ils résistent mieux au typhus, ce qui permet à Charles Nicolle, Charles Comte et Ernest Conseil, en 1911, d'entretenir la souche par des passages successifs, après avoir testé la sensibilité d'autres animaux et d'ectoparasites jusqu'à leur démonstration de la transmission exclusive de l'agent du typhus exanthématique par le pou humain en $1909^{21}$. Sans doute le parallélisme entre les deux maladies a déjà commencé à cette date dans l'esprit de Charles Nicolle. La même expérience que pour le typhus est tentée pour la peste: des poux ont été nourris sur un malade en phase septicémique et leur broyat injecté à deux cobayes, un gros et un petit, qui décèdent, le petit ayant mieux survécu ${ }^{22}$.

Jusqu'en 1920, la peste est discrète à Tunis et à Alger: tout au plus quelques cas humains sporadiques en relation avec des épizooties portuaires. Ils font l'objet de publications où se trouve l'amorce de l'hypothèse de la «route du grain» disséminatrice de peste en Afrique du Nord, qui sera remise à l'honneur plus tard ${ }^{23}$. Le Maroc est, quant à lui, victime en 1911 de la peste dite de Doukkala se déplaçant du sud vers le nord, avec des milliers de décès. Paul Remlinger, nouveau directeur du jeune Institut Pasteur de Tanger, s'est sans doute souvenu de sa conférence de Tunis lorsqu'il décrit, en 1913, une nouvelle entité épidémiologique locale, «la peste du nomade» du sud marocain à forme bubonique plutôt bénigne. La concordance entre les foyers de propagation de la peste et du typhus fait évoquer l'hypothèse d'un nomade réservoir et propagateur de maladies ${ }^{24}$.

C'est en 1920 que la peste nord-africaine dévoile ses deux visages. La peste portuaire, importée, est illustrée par le débarquement près de Bizerte, en janvier 1920, des reliquats de la flotte militaire du tsar Nicolas II avec dix cas à bord en relation avec une épizootie. La même année, et presque simultanément en Algérie et en Tunisie, des foyers ruraux endogènes de peste bubonique sont identifiés dans le centre et le sud pré-désertique avec des décès humains. L'épidémie fut d'abord observée par le médecin des mines de Redeyef,l'éclectique Ernest Gobert, passionné de préhistoire, qui a déjà eu l'oc-

21 Les frères Sergent de l'Institut Pasteur d'Alger ont contesté la primauté de cette découverte. L'originalité de l'équipe de Tunis est d'avoir réussi la reproduction du typhus sur le bonnet chinois et d'avoir étudié le comportement du bacille chez des animaux de laboratoire. Le seul point litigieux qui sera élucidé plus tard porte sur les modalités précises de pénétration du microbe à travers la barrière cutanéo-muqueuse: en 1909, on pensait que la piqûre de pou était seule virulente alors qu'en fait, ce sont surtout ses déjections. La concurrence entre les deux instituts frères a été d'autant plus âpre que les équipes travaillaient sur les mêmes pathologies et dans un même contexte et qu'Alger avait le soutien de la Rue Dutot: Nicolle/Comte/Conseil 1909.

22 Charles Nicolle, Cahier de laboratoire 1910, 2 juillet, p. 115.

23 La route du grain sera l'hypothèse privilégiée pour expliquer, en 1940, quelques cas groupés inexpliqués à Ferryville en Tunisie et la diffusion de la peste du Sous vers Casablanca, au Maroc.

24 Remlinger 1913; Renaud 1923; Raynaud 1923; Raynaud 1924. 
casion d'observer et de décrire une épidémie de typhus dans un bassin minier de la région de $\mathrm{Gafsa}^{25}$. Les résultats des enquêtes immédiates et approfondies menées par lui avec Lucien Raynaud en Algérie identifient les liens entre les cas de peste mais ne retrouvent pas l'origine de l'épidémie: pas d'épizootie et pas de bacille isolé chez les rats et les rongeurs capturés ${ }^{26}$. L'hypothèse d'une endémie est évoquée et les recherches sur la peste prennent un nouveau tournant à la demande expresse de Charles Nicolle. Des études sur l'histoire de la maladie dans la région sont entreprises et des enquêtes zooentomologiques sont effectuées pour identifier un réservoir et/ou un vecteur naturel local. L'enquête d'Ernest Conseil de 1908 sera complétée par celles, plus vastes, de Wassilieff, Ristorcelli et Reynaud en Tunisie et en Algérie entre 1924 et 1934: les rongeurs et leurs ectoparasites seront répertoriés et classés avec leur famille, espèce, répartition et biotope. Cette systématique sera approfondie ultérieurement par différents auteurs ${ }^{27}$. Un muridé, le psammomys, est particulièrement suspecté d'être à l'origine du foyer ${ }^{28}$. Dans son cahier de laboratoire de 1920, rédigé avec son écriture illisible, Charles Nicolle note: «nouvelle souche de peste» ${ }^{29}$.

Un troisième visage de la peste se manifeste à partir de 1924, la peste pulmonaire. Divers foyers primitifs, urbains et extensifs apparaissent successivement dans des villes du sud puis du centre du pays puis finalement dans la capitale entre 1925 et 1930 . Pour chaque épisode, les cas index sont des individus appartenant à un même groupe nomade originaire du Sud ou de la Tripolitaine. A cette occasion, Nicolle et Gobert cosignent un article dans lequel ils donnent un point de vue sur un sujet très discuté par la communauté scientifique internationale: celui des facteurs associés au déclenchement des épidémies de peste pulmonaire primitive ${ }^{30}$. Les auteurs incriminent le virus de la grippe.Alors que le bacille de Pfeiffer, agent de la pneumonie, était tenu pour responsable de la pandémie de grippe, Charles Nicolle, en 1917, démontre la nature filtrante «virale» de l'agent ${ }^{31}$.

25 Moulin 2007.

26 Gobert 1921; Raynaud 1924.

27 Raynal/Wassilieff 1932; Wassilieff 1932; Wagner/Wassilieff 1933; Ristorcelli 1938.

28 Suite à l'identification par Ricardo Jorge, en 1927, de foyers naturels de peste, une étude sur les rongeurs sauvages susceptibles expérimentalement à la peste fut menée dans les trois pays d'Afrique du Nord. Une espèce de la famille des gerboises (Jaculus jaculus L.), et trois espèces de la famille des gerbilles (Psammomys, Meriones shawi et libycus) se révélèrent sensibles. Leur répartition géographique correspond grossièrement aux foyers humains subdésertiques identifiés en 1920. Jorge 1928.

29 Charles Nicolle, Cahier de laboratoire 1920, juillet et octobre, p. 65, 111 et 112.

30 Nicolle/Gobert 1924. La peste des trappeurs de marmottes en Mandchourie d'octobre 1910 s'est étendue rapidement en Europe par le Transsibérien et a été le point de départ d'une série de foyers pulmonaires primitifs dans le monde, notamment en Egypte, à partir de 1920.

31 Nicolle/Lebailly 1918; Nicolle 1925; Nicolle 1935b. 
Les associations microbiennes étaient connues particulièrement depuis l'expérience de Metchnikoff sur le «microbisme latent» montrant que le vibrion cholérique n'est virulent que lorsqu'il est associé, dans le tube digestif, à des germes saprophytes. Maurice Nicolle appellera «microbes de sortie», les microbes qui ne se manifestent qu'à l'occasion d'une infection intercurrente. Charles Nicolle s'intéresse aux associations virus-bactéries. L'hypothèse de l'association de l'agent de la grippe et de la peste pulmonaire a été étayée par deux arguments épidémiologiques: la concordance géographique entre les foyers de grippe et de peste pulmonaire en Tunisie et l'intrusion nouvelle du virus de la grippe dans l'hemisphère Sud. Pour renforcer cette hypothèse, Ernest Conseil et Paul Durand vont s'atteler à montrer que le bacille de la peste peut loger dans les ganglions humains d'une manière asymptomatique pendant plusieurs mois ${ }^{32}$.

La peste pulmonaire de janvier 1930 à Tunis représente la dernière menace sérieuse ${ }^{33}$. La catastrophe fut évitée de justesse: juste quelques 60 décès en un mois de mobilisation maximale comprenant des mesures autoritaires d'isolement draconien des malades et sujets contacts et l'application de la séro-vaccination antipesteuse. De folles rumeurs circulèrent dont celle, persistante, que les malades se seraient contaminés en mangeant des sauterelles $^{34}$. En mars 1930, alors que l'on venait de découvrir dans les champs le cadavre du dernier fuyard pestiféré, Charles Nicolle déclara solennellement le bacille de la peste «déchu» ${ }^{35}$. Un grand quotidien de la place ouvrit de manière inédite ses colonnes à Béchir Dinguizli, premier médecin tunisien musulman, qui exhortait ses coreligionnaires à ne plus déroger aux principes universels de l'hygiène moderne et à les introduire dans les lieux de culte et de convivialitée ${ }^{36}$. En juin 1930, Ernest Conseil, rongé depuis plusieurs années par l'ostéomyélite et la morphinomanie, décéda d'épuisement sur le champ de bataille de la peste (ou presque), et les Tunisiens musulmans lui rendirent

32 Conseil/Durand 1927; Durand 1931.

33 Conseil/Durand 1930.

34 La Tunisie est un pays connu pour ses rumeurs. Celles-ci sont des métaphores ou un condensé de faits plus ou moins réels. Dans le cas de figure, l'évocation des sauterelles se réfère soit aux textes bibliques ou Saint Augustin, soit aux habitudes des gens du sud de manger des sauterelles grillées, soit au souvenir du passage en Tunisie en 1914 de Félix d'Herelle, un des découvreurs du bactériophage, pour un essai infructueux de lutte biologique contre les sauterelles. Il appliquera plus tard à Alexandrie la phagovaccinoprophylaxie antipesteuse des pèlerins par voie aéro-nasale, mode d'administration identique à celui utilisé par l'Institut Pasteur de Tunis au cours de l'épidémie de 1930 mais avec des germes tués.

35 Duhamel 1935. L'auteur, médecin-écrivain, est un ami de Charles Nicolle. Il a immortalisé sa première visite en Tunisie en 1920 dans son roman Le prince Jaffar.

36 Dinguizli 1930. 
un hommage déférent comme à un véritable martyr. Tunis est alors le nombril du monde des sciences médicales depuis que, contre toutes les attentes, «Charles Nicolle de Tunis», surnommé «le fourbe» par les frères Sergent d'Alger, a reçu son prix Nobel ${ }^{37}$.

L'état de vigilance permanente à l'égard de la maladie fait dire à Charles Nicolle qu'aucun cas de peste humaine depuis le début de la colonisation n'a échappé aux services médicaux. Tous ont été recensés, décrits selon divers paramètres et rapportés dans des séries statistiques. En Tunisie, pour la période de 1907 à 1931, il y eut au total 1522 cas de peste, dont 1359 buboniques et 167 pulmonaires, ayant causé 589 décès, soit $30 \%$, en dehors de tout traitement reconnu comme efficace. Sur les 50 foyers épidémiques recensés à travers le territoire, on retrouve une majorité de formes mixtes (buboniques et pulmonaires) et $1 / 5$ de foyers pulmonaires primitifs ${ }^{38}$. Les chiffres sont à peu près similaires en Algérie et en Libye ${ }^{39}$. Au Maroc, du fait de la grave épidémie de 1911 et de la persistance de petits foyers locaux encore mal connus, on compte 28000 décès. Pendant cette période, 10 à 20 fois plus de cas de typhus ont été recensés avec une mortalité estimée à $15 \%$, tandis que la grippe marquait lentement sa progression vers le sud. Les recherches pasteuriennes du début du siècle vont aider à mieux connaître la peste nord-africaine tout d'abord en la différenciant du typhus exanthématique.

\section{Le cycle naturel de la peste et du typhus africain}

Peste et typhus exanthématique sont des maladies très anciennes, probablement longtemps confondues, et qui se manifestent habituellement par des petites épidémies localisées mais qui, par temps de disette, de guerre et de grandes migrations, peuvent s'étendre et être à l'origine de véritables hécatombes humaines ${ }^{40}$. Le typhus exanthématique resta longtemps mal différencié des autres maladies contagieuses. Les progrès de l'anatomopathologie au XIX ${ }^{\mathrm{e}}$ siècle contribuèrent à le distinguer de la fièvre typhoïde (mise en évidence du rôle des plaques de Peyer dans cette dernière maladie en 1838),

37 Charles Nicolle était aussi surnommé le babass (le curé) par le personnel indigène de l'Institut Pasteur.

38 Gobert 1932.

39 Raynaud 1924. Les cas recensés en Libye étaient portuaires et l'hypothèse de l'importation a prévalu jusqu'en 1970.

40 L'usage du mot typhus revient aux guerres napoléoniennes. Le terme englobait toutes les fièvres avec des troubles nerveux. En Amérique latine, le typhus est désigné par le terme populaire de tabardillo. Divers termes savants lui seront aussi consacrés: fièvre puncticulaire, peste à pétéchies, fièvre des navires, fièvre des bagnes: Conseil 1907a; Jorge 1920; voir aussi Netter 1905. 
la bactériologie et la sérologie à la fin du XIX $\mathrm{X}^{\mathrm{e}}$ siècle de la peste, de la méningite cérébrospinale et autres fièvres exanthématiques (fièvres récurrentes, brucellose, rougeole, scarlatine). Néanmoins l'agent du typhus resta méconnu jusqu'aux années 1960 à cause de sa petite taille qui le rendait invisible au microscope ordinaire et beaucoup de savants, dont Charles Nicolle, supputaient sa nature ultrafiltrable, virale. En dépit des carences techniques de l'époque et de la régression séculaire de la maladie dans le monde, les connaissances scientifiques sur le typhus marquèrent des progrès substantiels au début du $\mathrm{XX}^{\mathrm{e}}$ siècle, en particulier grâce à la coopération du réseau international du typhus, constitué au milieu des années 1920, qui comprenait, outre l'équipe de Tunis, les équipes du Mexique (Hermann Mooser), de Pologne (Rudolph Weigl) et des Etats-Unis (Hans Zinsser). Cette collaboration permit de distinguer les différentes formes cliniques et les variétés de typhus dans le monde avec leur réservoir et leur vecteur et ainsi détacher ce groupe relevant de catégories nosologiques spécifiques. Ces recherches revêtent une grande importance pour le rétro-diagnostic et les recherches historiques sur la peste, du fait de ses similitudes avec le typhus exanthématique. En effet, jusqu'à l'ère bactériologique, seul le bubon pesteux permettait de distinguer ces deux maladies, mais il n'est ni constant ni pathognomonique. Des particularités épidémiologiques locales les distinguent aussi.

\section{Un nomade réservoir et propagateur de maladies}

Le réservoir du «typhus africain» est localement représenté par des communautés semi-nomades très anciennes vivant isolées en altitude. Leurs membres présentent des infections inapparentes de récidive, bénignes mais transmissibles par le pou. Des petits foyers ruraux se déclaraient annuellement dans leur sillage mobile au moment des transhumances. Contrairement aux épidémies de peste dont les apparitions sont irrégulières et séparées par des intervalles plus ou moins prolongés, les épidémies de typhus sont périodiques, annuelles ou biannuelles. Certaines communautés locales rurales connaissaient ces «fièvres printanières» qu'elles appelaient de noms variés et le rôle propagateur du nomade était suspecté. Ces épisodes disparaissaient avec l'arrivée des chaleurs estivales alors que la peste aurait eu une tendance à la recrudescence en été. Parfois, le typhus réapparaissait en automne au moment où ces mêmes nomades prenaient le chemin du retour, avec des haltes aux abords des villes pour faire leurs provisions d'hiver. Exceptionnellement, les cas urbains, peu nombreux habituellement, se multipliaient jusqu'à la période du froid pour prendre la forme de véritables épidémies urbaines. Celles-ci suc- 
cédaient, en général, à des années de catastrophes naturelles (famine, épizooties dans le cheptel) ou de troubles qui faisaient affluer les nomades vers les villes, gonflant les populations de mendiants et de miséreux entassés dans les faubourgs ${ }^{41}$. Un adage dit: «Après la famine, la peste.» Ces grandes épidémies de typhus restaient rarement limitées à une ville, le plus souvent elles débordaient les frontières pour atteindre les principales cités du Maghreb. Ce fut le cas des épidémies de 1861 (Kabylie, Oran, Bougie, Constantine), 1868 (toute l'Afrique du Nord), 1885-1888 (Alger, Kabylie, Aurès, Constantine), 1892 (Cyrénaïque et Tripolitaine), 1898 (Maroc), 1908-1909 (Constantine, Tunisie, Biskra), 1919-1923 (Oran, Maroc, Laghouat) ${ }^{42}$. En effet les populations tribales occupaient des territoires quasi autonomes et souvent limitrophes entre les pays, et l'on peut dire qu'en ces temps éloignés, aussi bien la peste que le typhus n'avaient pas d'autres frontières que les frontières naturelles.

Cependant, les foyers endémiques de peste et de typhus ne sont pas superposables géographiquement. Ceux de la peste ont été localisés dans des territoires nomades de régions subdésertiques, avec à l'est le foyer libyen et à l'ouest le foyer du nord-est de la Mauritanie et dans des poches de basse altitude dont le biotope est particulier: il serait à la fois favorable à la survie du bacille, occupé par certaines espèces de rongeurs sensibles à la peste et recherché aussi par les caravaniers pour leurs haltes à cause de la disponibilité de points d'eau et de certaines espèces de plantes succulentes prisées par les dromadaires ${ }^{43}$. Les six zones d'endémie de typhus ont été délimitées dans des régions montagneuses du nord de l'Atlas présaharien: le foyer d'Oujda, près de Tlemcen sur la frontière marocaine, le cercle de Meliane près d'Alger, le cercle de Laghouat près de Biskra, le cercle de l'Aurès près de Batna, le cercle de Kabylie près de Bougie et celui d'Edough dans le triangle Bone-La CalleConstantine. Outre le Maghreb, d'autres foyers endémiques du pourtour méditerranéen ont été identifiés dans le sud de l'Espagne et du Portugal, en Sicile, dans les Balkans et en Egypte ${ }^{44}$. Dès lors, on peut supposer que le bacille du typhus tout comme celui de la peste circulait en Méditerranée avec une intensité proportionnelle aux progrès de la navigation, à l'accroissement du trafic maritime et du nombre de voyageurs.

Le mode de propagation du typhus et de la peste n'est cependant pas similaire dans le contexte particulier des sociétés traditionnelles maghrébines.

41 Conseil 1907b; Conseil 1910; Conseil 1911b.

42 Raynaud 1923.

43 Voir Klein et al. 1975.

44 Jorge 1920. En 1915, alors que le typhus exanthematique avait disparu du territoire, une épidemie de typhus importé, éclate dans un camp de refugiés serbes dans la region de Bizerte. 
La grande épidémie de typhus de 1909 à 1910 a été particulièrement observée par Ernest Conseil ${ }^{45}$. Le typhus touche sélectivement la population des bagnes, des asiles, des migrants ainsi que des groupes vivant dans des conditions de grande promiscuité. Les cas chez les citadins de souche sont très rares (un cas par rue, par maison) et l'origine de leur contamination est le plus souvent inconnue: possible visite chez le coiffeur, halte dans un café populaire ou autre lieu de convivialité. Par comparaison, les observations depuis la peste noire s'accordent pour dire que la peste ne fait pas de distinction sociale et que les atteintes se font en grappe avec une progression aléatoire: un individu puis une famille puis une maison puis une rue; certains individus ou certains blocs de maisons sont épargnées dans des quartiers où la peste a déjà tout emporté ${ }^{46}$.

La présence endémoépidémique du typhus au Maghreb a été révélée au $\mathrm{XIX}^{\mathrm{e}}$ siècle par les nouveaux migrants européens. La mortalité due au typhus est très élevée chez les gens de peau noire et d'origine européenne, ainsi que chez les individus débilités comme les personnes âgées. Elle est faible dans les autres groupes de population, et particulièrement les enfants chez qui les cas de décès sont exceptionnels. Le typhus touche plus les hommes que les femmes, contrairement à ce qui a été rapporté sur certaines pestes médiévales du Moyen Orient.

Les connaissances acquises au début du $\mathrm{XX}^{\mathrm{e}}$ siècle sur les manifestations spécifiques de la peste et du typhus permettent une meilleure interprétation des témoignages écrits anciens. Dès la fin du XIX ${ }^{\mathrm{e}}$ siècle et début du $\mathrm{XX}^{\mathrm{e}}$ siècle, les mémoires congrégationistes (abbé Vicherat et abbé Poiret), de voyageurs médecins du XVIII ${ }^{e}$ et XIX ${ }^{e}$ siècle (Peysonnel, Desfontaines, Shaw, Frank Louis, Paul Dunant), les correspondances consulaires, les traductions d'ouvrages d'historiens arabes (Ibn Khaldun, Ibn Dinar El Kairouani, El Aïachi) ou latins (Saint Cyprien, Saint Augustin) sont publiés, où l'on retrouve décrites des périodes de grandes épidémies à travers les siècles. Ces sources écrites ont été à la base des reconstitutions médico-historiques effectuées par les médecins de la colonisation qui sont restées jusqu'à aujourd'hui la principale référence des études contemporaines ${ }^{47}$. Exception faite de quelques pestes vraies qui ont donné lieu à de véritables observations commentées dans certaines villes et certaines années et dans lesquelles la présence de bubon ou de ta'un ne fait pas de doute ${ }^{48}$, ce sont plutôt des

45 Conseil 1910; Conseil 1911a.

46 Conor 1911; Conor 1914-1916.

47 Marchika 1927; Bloch 1929; voir aussi la série d'articles «Recherches historiques sur la peste au Maroc», de H. P. J. Renaud, parus en particulier dans la revue Hesperis entre 1921 et 1934.

48 La peste noire au Maghreb eut pour témoin des narrateurs célèbres: Ibn Khaldun (historien et philosophe tunisien), Ibn Battuta (géographe et voyageur d'Andalousie), Ibn Khatib et 
épisodes de surmortalité attribués à la peste qui sont évoqués à travers les représentations et le système de croyances de l'époque. Pour Charles Nicolle et ses collaborateurs, certaines descriptions anciennes correspondent davantage aux caractéristiques cliniques et épidémiologiques du typhus. Les épisodes de mortalité épidémique des guerres puniques relatés par Saint Augustin et Paul d'Orose évoquent le typhus. La peste de Saint Cyprien au $\mathrm{IV}^{\mathrm{e}}$ siècle serait en fait un typhus, d'après les observations laissées par ce même auteur. Les épitaphes funéraires datant du III ${ }^{\mathrm{e}}$ siècle avec la mention «pestis» retrouvées près de la cité d'Hadrumète et de Carthage par le père Delattre en 1905 ne désigneraient pas la peste. Saint Louis ne serait pas mort de peste en 1270 à Tunis mais, d'après les détails relatés par Michelet et les sources arabes, d'empoisonnement, de blessures, de dysenterie ou de paludisme.

\section{La peste sans rat: hypothèses explicatives}

Autant, pour le typhus exanthématique, la littérature pasteurienne offre un cadre explicatif d'une puissante cohérence, autant, pour la peste, cette même littérature semble hésiter entre plusieurs hypothèses quant à l'origine de la surmortalité des pestes médiévales. De nombreuses recherches ont tenté de la justifier. L'efficacité vectorielle de la puce de rat étant reconnue comme faible d'après les travaux expérimentaux, par quels mécanismes compensateurs la peste a-t-elle pu tuer autant de gens en de si courtes périodes? On explique aujourd'hui les grandes épidémies urbaines par une surmortalité exceptionnelle chez le rat domestique. Elle libèrerait une population anormalement élevée de puces pestigènes qui vont coloniser d'autres hôtes dont l'homme. Cette hypothèse explicative suggère que dans les épidémies, la transmission de la peste par voie cutanée est prédominante et que la piqûre par puce de rat infecté est la source principale de la contamination humaine. Pourtant les observations anciennes sur les pestes nord africaines ne relèvent pas de surmortalité chez le rat, phénomène qui aurait dû être bien visible dans les cités arabes médiévales du fait de leur urbanisme et de leur architecture particulière. Des bubons ont été constatés chez des animaux familiers comme les chats, les chiens, le chameau, mais le rat n'apparaît pas comme fac-

Ibn Khatima (médecins d'Andalousie). La peste de 1785 à Alger et Tunis fut bien décrite par le père Vicherat, qui la contracta deux fois en un an d'intervalle et pratiqua des autopsies: voir Conor 1911. Celle de 1818 eut de nombreux témoins de diverses nationalités dans différentes villes du Maghreb, voir Sebag 1965, Renaud 1923. 
teur étiologique dominant ${ }^{49}$. Au début du $\mathrm{XX}^{\mathrm{e}}$ siècle, les rashs épizootiques portuaires sont rares et de faible intensité y compris au cours de la grande épidémie de peste bubonique de Casablanca de 1940.

Pour Charles Nicolle, les épidémies sont des hasards, c'est-à-dire résultent d'une succession de facteurs dont la survenue est, prise isolément, peu probable, mais qui se répètent; et c'est l'homme qui les provoque: pas de pou, pas de typhus, mais aussi, si l'homme ne se gratte pas, pas de typhus, pas de fièvres récurrentes, moins de peste aussi probablement. La pénétration d'un microbe par voie transcutanée se fait par contact entre les muqueuses et une population microbienne. La piqûre d'un ectoparasite infecté n'est qu'un des mécanismes de pénétration, mais pas le seul. Il suffit qu'une peau soit excoriée pour augmenter la surface muqueuse en contact avec les bacilles de l'environnement (déjections ou produits de régurgitations du bouchon muqueux de la puce infectée, poussières, crachats et aérosols par exemple). La présence de plaies ou d'excoriations cutanées chez les individus multiplie les risques de survenue d'une peste bubonique, ce qui est fréquent par temps de guerre ou par suite de certaines habitudes humaines comme le grattage, les scarifications, la pose de ventouses, des pratiques d'hygiène orientales telles que le rasage, l'épilation, le dégommage de la surface corporelle.

Trois hypothèses relatives aux pestes médiévales sont retrouvées dans la littérature pasteurienne de l'époque, chacune appelant des commentaires. La première hypothèse attribue un rôle vecteur au pou et à la puce de l'homme dans la transmission de la peste. Elle fut envisagée par Charles Nicolle et reprise en 1943 par Georges Blanc et Marcel Baltazard. Ces auteurs ont proposé un nouveau modèle régional d'épidémisation: les premiers cas seraient dus à des piqûres de puces de rat, puis le relais est pris par les ectoparasites humains ${ }^{50}$. La peste serait donc comme le typhus une maladie liée à l'ectoparasitisme humain. Ce modèle de transmission explique cependant imparfaitement les épidémies de peste exclusivement pulmonaire. De plus, il donnerait aux épidémies urbaines de peste un caractère proche de celles du typhus $^{51}$. Une deuxième hypothèse attribue la surmortalité des pestes

49 Le bubon du chameau, gudda, est connu depuis longtemps dans la péninsule arabique et il est assimilé au bubon pesteux de l'homme. La maladie du rat, phénomène pourtant relevé par Avicenne au Xe siècle et anciennement connu de certaines communautés hindoues et chinoises, ne semble pas avoir retenu l'attention des observateurs, aussi bien en Europe qu'en Orient musulman: Aroua 1974; Moulin 1996. L'absence de visibilité des épizooties par les anciens est aussi expliquée par le fait que les rongeurs malades sont des proies faciles pour les prédateurs, dont le chat qui était le seul animal domestique familier dans les médinas.

50 Blanc/Baltazard 1945.

51 De nombreuses observations épidémiologiques ont été relatées sur les épidémies de peste en Afrique du Nord. On y retrouve la notion d'exposition professionnelle à la peste: les porteurs d'eau et d'huile sont épargnés tant qu'ils ne se débarrassent pas de leur enduit grais- 
médiévales à la présence concomitante d'autres causes de morbidité, dues, par exemple, à d'autres maladies contagieuses comme la variole ou le typhus. Ce fut probablement le cas en 1818 de la «peste» à Tunis ${ }^{52}$. En effet, pour les deux maladies, l'immunité individuelle est brève (un an) et non croisée et un individu peut être atteint plusieurs fois dans sa vie par l'une d'elle ou être atteint tour à tour par chacune d'elle. Ce qui rend plausibles les «hasards» d'épisodes épidémiques communs, d'autant que la chaîne de transmission des deux maladies fait intervenir une même entité sociologique locale, le nomade et qu'elles essaiment dans un contexte de misère physiologique collective. Enfin, une dernière hypothèse évoque la prédominance des formes pulmonaires dans les épidémies urbaines, très contagieuses et souvent fatales, décrites dès le $\mathrm{VII}^{\mathrm{e}}$ siècle par les médecins byzantins puis par les médecins arabes du Moyen Age. Cette hypothèse est privilégiée par Charles Nicolle. Les premiers cas sont buboniques, puis le relais est pris par la transmission aérienne facilitée par le mode de vie et les coutumes musulmanes qui donnent de multiples occasions de rassemblements propices à la contagion directe. La survenue d'une épidémie de grippe peut relancer la contagion car les individus porteurs asymptomatiques du bacille de la peste développent une pneumonie à l'occasion d'une infection intercurrente par la grippe. Le cycle de contamination s'arrête au moment où une majorité de la population survivante est naturellement immunisée contre une nouvelle vague de peste rapprochée ${ }^{53}$.

\section{Les lois d'évolution des infections et l'histoire universelle de la peste}

Outre l'approche épidémiologique et sociologique de la peste et du typhus qui lui a permis de clarifier la situation régionale de chacune des maladies,

seux cutané; les préposés aux bains maures, les professions assises, comme les tisserands ou les érudits, sont plus exposées. Les nouveaux migrants noirs se sont révélés très sensibles à la variole, à la peste (typhus?) et résistants à la syphilis. Le fait que les femmes et les enfants soient plus exposés, laisse penser à une exposition par des gestes précis réservés aux femmes (comme le dépoussiérage, le balayage, la préparation de la provision annuelle des grains de semoule qui se fait en été) dans leur univers confiné, avec les enfants ou la présence du chat dans les espaces domestiques. L'architecture des intérieurs, peu aérée et peu ensoleillée, est sans doute aussi favorable à la survie du bacille.

52 En 1818, à Tunis, les premiers foyers sont cantonnés dans les faubourgs nord de la ville où des communautés migrantes (noirs, nomades, Algériens) vivent entassées. Les médecins italiens du bey sont divisés sur le diagnostic de typhus. On remarque déjà que les mendiants propagent la maladie sans la contracter. Au bout de près d'un an, des bubons sont reconnus à l'hôpital musulman chez des malades originaires de Constantine et la peste est déclarée officiellement par le médecin personnel du bey.

53 Ce phénomène est appelé aujourd'hui herd immunity ou immunité de groupe. 
Charles Nicolle a, au fil des ans, élaboré un cadre conceptuel dans lequel la peste s'intègre à une histoire universelle des microorganismes vivants. Sa loi des cycles est devenue classique: le microbe est un être vivant qui naît, cherche à survivre dans son environnement, se multiplie en se différenciant à chaque génération, s'adapte à différents hôtes et disparaît en un temps plus ou moins long. Par extrapolation, chaque maladie infectieuse suit un cycle de vie millénaire avec une naissance, une vie et une mort ${ }^{54}$. Dès la fin des années 1920, alors que Thomas Hunt Morgan fait entrer dans l'actualité la théorie de l'hérédité des êtres visibles en s'appuyant sur ses recherches expérimentales sur des drosophiles ${ }^{55}$, Charles Nicolle rassemble les preuves indirectes de l'existence d'une évolution des êtres invisibles en se fondant sur l'argument logique que seule cette hypothèse fournit une explication satisfaisante au polymorphisme clinique et épidémiologique constaté pour diverses infections comme la syphilis, la tuberculose ou le typhus ${ }^{56}$. En fin de vie, il évoquera ouvertement les bases génétiques de la physiologie des bactéries et des ultravirus avec l'idée d'une chaîne ininterrompue de formes matérielles microbiennes, des plus petites aux plus grandes, dont la reproduction obéit aux lois de la sélection naturelle et du hasard ${ }^{57}$.

\section{Peste et médecine expérimentale:}

l'interaction hôte-pathogène et la systématique des yersinioses

L'infection est un phénomène biologique d'adaptation progressive entre un organisme hôte vivant et un micro-organisme vivant et elle évolue dans le temps et l'espace. Charles Nicolle a essayé de rendre intelligible cette histoire naturelle en donnant une signification aux variations constatées du comportement des microbes et des réactions de l'organisme hôte dans les conditions naturelles et expérimentales. A l'échelle des siècles et des millénaires, il suggère qu'une grande sensibilité d'une espèce animale à une espèce microbienne ou apparentée est le signe d'un contact récent ou d'une mutation microbienne tandis qu'une plus ou moins grande résistance est le signe d'une adaptation ancienne. Le cobaye a été choisi par Charles Nicolle comme animal de laboratoire, non seulement parce qu'il est facile d'élevage

54 Nicolle 1937.

55 Morgan 1922.

56 Ben Néfissa 2006; Nicolle 1935b.

57 Burnet 1911. L'idée de «darwinisme microbien» évoquée par Metchnikoff en 1905 paraissait difficile à prouver à une époque où la plupart de ces microorganismes n'étaient pas visualisés ou cultivés, et de ce fait ne pouvaient être classés. Nicolle 1925; Nicolle 1935a; Nicolle 1935b; Nicolle 1935c. 
mais aussi parce que c'est un «individu neuf»: il est originaire du Nouveau Monde (du Pérou précisément) et, de ce fait, il n'a pas été au contact des microbes circulant dans le Vieux Monde méditerranéen. C'est en laboratoire et grâce à l'étude de l'infection expérimentale du cobaye que Charles Nicolle restitue les pièces manquantes de la mosaïque de l'histoire infectieuse: l'infection inapparente, conservatrice de microbes et immunisante naturelle, donc facteur de leur extinction ${ }^{58}$, le rôle des ectoparasites dans le cycle biologique des microbes, leur trajectoire parfois paradoxale et leur éco-évolution; le rôle de l'immunité et de la présence d'autres pathogènes.

Grâce à des recoupements entre les observations cliniques, biologiques, épidémiologiques dans la nature et en laboratoire, Charles Nicolle esquisse l'histoire universelle de divers microorganismes vivants dont certains n'étaient même pas identifiés avec précision. La peste, le typhus et les fièvres récurrentes sont des infections issues d'ancêtres microbiens vivant dans des terriers de rongeurs qui s'auto-infectent en mangeant leurs ectoparasites ou leurs congénères. L'ancêtre de l'agent de la peste s'est adapté à la puce du rongeur, ce qui a entraîné la naissance d'une nouvelle maladie. Le typhus ancestral, quant à lui, s'est divisé en deux branches autonomes, le typhus murin adapté à la puce de rongeur et le typhus exanthématique adapté au pou humain, par mutation génétique ${ }^{59}$. Tandis que l'agent des fièvres récurrentes a donné une multitude de branches adaptées à divers hôtes et ectoparasites (pou et puce) et, parmi elles, les branches issues de sa rencontre avec la tique, aujourd'hui appelées borrélioses ${ }^{60}$, qui présentent un tel degré de spéciation que chaque souche n'est adaptée qu'à un terrier de tique (avec sa descendance) et constitue une maladie quasi indépendante.

Partant de ces observations, Charles Nicolle rejette la classification fermée en espèces microbiennes et propose des critères d'approche variables tenant compte de l'évolution et du seul pouvoir spécifique du microbe, sa virulence, définie par lui comme un pouvoir d'adaptation au sein d'une mosaïque de pouvoirs. Cette conception, originale à l'époque, a sans doute influencé l'adoption d'une systématique adéquate au bacille de la peste. L'agent de la peste fut en effet classé, en 1924, dans le groupe des pasteurelloses avec Pasteurella tularensis, agent de la tularémie, autre maladie à bubons. En 1927, le hasard, encore une fois, fait croiser le destin de la peste et du typhus dans le

58 Correspondance Charles Nicolle - Félix Mesnil,1904-1909. C'est sur le «frémissement» d'un cobaye typhique que Charles Nicolle fait, en 1911, la plus importante de ses découvertes, l'infection inapparente: Nicolle 1935c.

59 Voir le débat entre Hermann Mooser et Charles Nicolle à propos de la phylogénie des typhus publié dans les Archives de l'Institut Pasteur de Tunis (1932) 1-24.

60 Nicolle 1935b; Rodhain 1989; Ben Néfissa 2006. 
laboratoire de l'Institut Pasteur de Tunis: Helena Sparrow, venue en Tunisie pour la mise au point d'un vaccin contre le typhus, était en train d'entretenir une deuxième souche tunisienne sur des cobayes, lorsque l'élevage fut presque décimé par un germe «bipolaire» jugé jusqu'alors inoffensif et surnommé bacille de la pseudo-tuberculose sans être plus classé que cela dans une famille microbienne. Sa parenté avec le bacille de la peste fut évoquée dès 1904 et Sparrow le rappelle dans un article sur l'événement ${ }^{61}$. En 1937, il est intégré au groupe des pasteurelles, mais, en 1945, Georges Blanc et Marcel Baltazard notent l'inadaptation de Pasteurella tularensis à la puce de rongeur, contrairement aux deux autres espèces, et proposent ce critère évolutif d'adaptation à l'ectoparasite pour la constitution du nouveau groupe des Yersinias, qui sera adopté en 1970. Les recherches expérimentales entreprises au Maroc en 1945 montrent aussi la possible transmission de la peste par des ectoparasites humains (puces et poux de corps) ${ }^{62}$. Nous ignorons le devenir des souches de peste isolées à Tunis, en particulier celle isolée à Ben Guerdane en 1920, qui s'est révélée très virulente sur le cobaye et le singe. Nous ne savons pas si elle appartenait à la variété régionale (medievalis ou antica) ou cosmopolite (orientalis).

\section{Le destin de la peste et du typhus, maladies de l'Ancien Monde?}

Il est impossible de connaître la date précise de l'apparition d'une maladie infectieuse, ne serait-ce que parce que toute maladie nouvelle se manifeste d'abord par des formes inapparentes, tout au plus peut-on estimer un intervalle probable entre les épidémies à travers les âges ${ }^{63}$. Charles Nicolle aimait à désigner le typhus exanthématique par les termes choisis de typhus historique ou typhus de l'Ancien Monde, par opposition au typhus murin ou typhus bénin ou encore typhus du Nouveau Monde. Il situait la division du typhus à une époque très lointaine, il y a plusieurs milliers d'années, au moment de la migration de communautés polynésiennes vers le nouveau continent. Son argument est biologique: le test sérologique de Weil et Felix, spécifique du typhus, se base sur la réaction de séroagglutination croisée entre l'agent du

61 Le bacille de la pseudo-tuberculose a d'abord été décrit par Malassez et Vignal en 1884. Sa parenté avec le bacille de la peste a été évoquée par Zlatogoroff (1904), Mac Conkey (1908) et Rowlan (1913). Sous le taxon actuel de Yersinia pseudotuberculosis, il est reconnu comme la branche phylogénétique ancestrale de Yersinia pestis et de Yersinia enterolytica, autre espèce commensale, tellurique et entéropathogène figurant aujourd'hui sur la liste des pathogènes émergents: Nicolle/Sparrow 1928; Chain et al. 2004; Achtman et al. 2004.

62 Blanc/Baltazard 1945.

63 Nicolle $1935 \mathrm{c}$. 
typhus et une souche particulière du Proteus X19, isolée dans les urines d'un malaisien et retrouvée exclusivement en Malaisie. Pour la peste, Charles Nicolle retient la date de la peste justinienne comme première manifestation de la maladie dans le bassin méditerranéen. Cette hypothèse admise encore de nos jours est justifiée par le fait que le bubon pesteux a été décrit par les contemporains et que le rat noir, réservoir de la peste, était absent jusqu'au $\mathrm{XI}^{\mathrm{e}}$ siècle dans la région. Mais Charles Nicolle relève également que certaines communautés locales restaient hors du champ d'observation des érudits anciens.

Les maladies s'éteignent par tarissement du réservoir ou du vecteur comme pour le typhus, ou par un phénomène d'immunisation collective comme pour la variole ou la poliomyélite. Leur agent continue à survivre au sein de l'hôte originel sous forme de saprophyte. Il peut redevenir pathogène dans des circonstances telles qu'une mutation, un déficit immunitaire, une rencontre synergique avec un autre pathogène. Charles Nicolle considère la peste, avec la grippe et le paludisme, comme une maladie non susceptible d'être éradiquée, en le justifiant par le fait que le réservoir est animal: rongeur pour la peste, oiseaux pour la grippe. L'explication n'est pas tout à fait convaincante, mais sans doute pas fortuite. Le bacille du typhus présente une grande spécificité d'hôte et de vecteur contrairement à celui de la peste, et il était aisé de prévoir l'extinction de la maladie avec l'éradication du pou. Celui de la peste est opportuniste: il aurait traversé les millénaires en s'y entendant pour coloniser différentes espèces d'hôtes vertébrés et invertébrés (sans compter le sol), mais toujours avec une virulence pratiquement identique chez l'homme et l'animal. Ce qui le distingue du typhus murin lié à un hôte spécifique, par exemple et rend imprévisibles ses péripéties. La prédiction qui était déjà partagée par un certain nombre de contemporains de Charles Nicolle, est aujourd'hui confirmée par les experts ${ }^{64}$.

\section{Faut-il réécrire l'histoire de la peste?}

La présence endémique ancienne de la peste et du typhus remet en cause le bien fondé des séries statistiques historiques sur la peste et certaines idées reçues. Certains indicateurs tels que le nombre d'années de peste par siècle ou la mortalité spécifique due à la peste par ville et par année se fondent sur des informations souvent peu fiables ou de simples présomptions: les Anciens n'avaient pas les moyens de distinguer les deux maladies et certains Euro-

64 Voir la mise au point récente par un groupe international d'experts: Stenseth et al. 2008. 
péens avaient tendance à désigner comme peste toutes les maladies épidémiques mortelles de causes indéterminées. Le fait que les cités portuaires aient été souvent touchées par des vagues épidémiques ne préjuge pas du caractère importé des maladies. Ces cités concentraient les élites urbaines et les minorités Européennes et de ce fait étaient davantage le point de mire. A l'inverse, certaines pestes vraisemblables ne semblent pas avoir retenu l'attention des historiens. Ainsi la «peste des Libyens» évoquée par Dioscoride au $\mathrm{I}-\mathrm{II}^{\mathrm{e}}$ siècle avec son tableau de tuméfactions fébriles à caractère épidémique pourrait évoquer la "peste du nomade» décrite au début du $\mathrm{XX}^{\mathrm{e}}$ siècle ${ }^{65}$. L'hypothèse est d'autant plus crédible que les nomades des peuplades barbares numides étaient connaisseurs, voire consommateurs de rongeurs pour leur chair séchée et leur fourrure, objet de transactions commerciales dans leurs randonnées. Au début du $\mathrm{XX}^{\mathrm{e}}$ siècle, ceux-ci désignaient le psammomys par le terme de sbouhi (le matinal) du fait sans doute de ses habitudes diurnes.

On admet que la peste justinienne s'est introduite à Carthage, mais sans document probant et sans aucune hypothèse sur la manière dont elle s'est introduite. Il n'est pas non plus certain qu'entre la peste justinienne et la peste noire, le fléau ait disparu des territoires du Maghreb ou du Proche Orient et que le fameux intervalle inter-épidémique de cinq siècles ait existé à l'instar de l'Europe ${ }^{66}$. Des épisodes épidémiques ont jalonné la conquête arabe de l'Afrique du Nord et le contexte particulier oriente vers le typhus, mais aucune hypothèse ne peut être retenue sans une étude au cas par cas. Autre fait troublant: Ibn Jazzar, médecin de Kairouan du $\mathrm{X}^{\mathrm{e}}$ siècle, et El-Sikilli, médecin de Tunis du $\mathrm{XV}^{\mathrm{e}}$ siècle, auraient écrit, chacun, un traité perdu relatif à la «peste en Egypte». Quelle signification donner à ces événements? Il semble que la peste noire n'ait pas produit les mêmes dégâts qu'en Europe, malgré ses nombreuses victimes au sein des élites; et en particulier, elle ne s'est pas étendue aux territoires nomades et villes de l'intérieur, sans doute faute de voies fluviales de communications, contrairement à l'Europe ou l'Egypte, ce qui est en faveur d'un mode d'épidémisation particulier au Maghreb faisant intervenir les routes caravanières. Léon l'Africain au $\mathrm{XV}^{\mathrm{e}}$ siècle pourrait

65 L'hypothèse qui fait remonter la présence de la peste en Méditerranée à une période antérieure à la peste justinienne peut encore être étayée par cette parole attribuée au prophète Mohamed qui fut contemporain de la peste justinienne: «La peste est un châtiment qui fut envoyé à un groupe des Beni Israël et à ceux qui ont existé avant vous ...» Par ailleurs, le rat noir pourrait avoir une présence très ancienne dans le pourtour méditerranéen: AudouinRouzeau 1999.

$66 \mathrm{Il}$ y eut d'autres intervalles inexpliqués entre les épidémies retenues par les historiens contemporains. Par exemple en Tunisie, entre 1705 et 1785, dans les trois pays du Maghreb entre 1820 et 1907, et plus récemment entre 1940 et 1972, puis en 1980 et en 2006 en Libye. 
avoir confondu les deux maladies quand il affirmait que la peste n'existe pas aux «pays des Noirs et en Libye», ou quand il évoquait le caractère périodique des épidémies de peste dans les cités nord africaines ${ }^{67}$. Il semble qu'à partir du XV ${ }^{\mathrm{e}}$ siècle les Arabes aient retenu le terme de ta'un pour désigner spécifiquement la peste ${ }^{68}$. Les traductions des ouvrages d'historiens arabes ont-elles tenu compte de la distinction entre waba et ta'un? La grande peste de 1705 en Tunisie a-t-elle eu les caractéristiques épidémiologiques d'une vraie peste? Qu'en disent les sources hagiographiques arabes de l'époque? Mentionnent-elles le ta'un? Les vagues épidémiques décrites un peu partout sur le territoire nord-africain entre 1785 et 1818 étaient-elles dues à la peste et ont-elles eu la gravité qui leur est attribuée? ${ }^{69}$ Qu'en a-t-il été réellement de la fameuse "peste d'Orient» et des épidémies du Hijjaz aux XVIII" et XIX ${ }^{\mathrm{e}}$ siècles? Pourquoi, par exemple, dans les années de pèlerinage, la «peste» ne franchissait-elle pas le triangle sacré ${ }^{70}$ Les descriptions faisant état de navires bondés de voyageurs "pestiférés» suggèrent-elles la présence de rats pesteux à bord? D'un réservoir humain ectoparasité? D'une source alimentaire insalubre? Pourtant, ces descriptions confuses ou de simples rumeurs suffisent à faire évoquer la peste et à comptabiliser des années d'épidémie dans des endroits parfois éloignés du lieu initial d'observation. Ces remarques invitent à une relecture des textes anciens, au recoupement entre les sources arabes et européennes, sources littéraires et scientifiques, à des études poussées sur l'histoire locale, étant donné la grande diversité écologique et populationnelle du Maghreb de l'époque. Cette méthode déjà privilégiée par Charles Nicolle pour ses réflexions académiques pourrait permettre de proposer des hypothèses à des énigmes biologiques actuelles telles que le lien entre les foyers endémiques libyen et mauritanien, leur période d'endémisation probable, la cascade d'événements à l'origine des premiers cas humains à partir des foyers naturels ou la manière probable dont Yersinia pestis et ses variantes se sont disséminés sur le territoire.

67 Léon L'Africain 1956.

68 Saadaoui 1995. L'année 1522 dans le Sous marocain est celle du ta'un el kébir (grande peste). 69 Speziale 1997.

70 Le triangle sacré est une zone délimitée aux abords de la Mecque, où les pèlerins se rendaient avant de franchir les portes de la ville sainte, pour se laver, se raser de près, se débarrasser de leurs habits et se recouvrir le corps d'une tunique blanche immaculée. On peut rapprocher cette scène coutumière de la «vision» alléguée par Charles Nicolle au moment de pénétrer dans l'enceinte de l'hôpital musulman après avoir enjambé le corps de malades typhiques gisant sur les escaliers. «C'était le pou, ce ne put être que le pou», racontera-t-il vingt ans plus tard dans son discours du Nobel de 1929. En effet, les malades, avant d'être admis dans les services, étaient lavés, rasés et habillés d'une tunique en toile et ils cessaient d'être contagieux car debarassés de leurs ectoparasites: il n'y avait jamais de cas de contagion à l'intérieur de l'hôpital. Cette «vision» a été diversement commentée par les historiens: Moulin 1994. 
La disparition progressive de la peste et du typhus au nord de l'Afrique a correspondu aux nouvelles mesures de prophylaxie internationale et scientifique, mais aussi à la désertification, à la réduction des espaces naturels réservés aux nomades pasteurs, porteurs de poux et amis des rongeurs. Cette extinction s'est aussi accompagnée de la montée de «maladies d'avenir» telles que la fièvre de Malte (brucellose), d'un remplacement dans les villes portuaires du rat noir par le rat gris (moins sensible et moins propagateur de peste), de l'apparition du bacille de la pseudo tuberculose chez les rats du port de Tunis, de la progression régulière de la leishmaniose dont le réservoir rongeur est représenté par deux gerbilles sensibles à la peste. Fin d'une pathocénose ou victoire de l'homme contre un bacille? Aujourd'hui encore, l'agent du typhus exanthématique et celui de la peste continuent à se maintenir sur le plateau du Tibet et du Yunnan, leur probable berceau d'origine ${ }^{71}$. L'agent de la peste rappelle périodiquement sa présence en territoire nord-africain par quelques cas humains groupés de «peste des Libyens», malgré l'extinction du nomadisme. Ceux qui ont visité quelques poches de terroirs arides suspects le disent très proche de certaines espèces de rongeurs, phylogénétiquement apparentées, vivant en colonies peu nombreuses et mobiles, parfaitement adaptées aux conditions extrêmes des zones subdésertiques. Les derniers foyers épidémiques connus de peste en Afrique du Nord sont le foyer d'Oran de 2003 (10 cas) qui serait importé et le foyer tout récent de Tobrouk de juillet 2009 (18 cas) en Libye, sur la frontière avec l'Egypte, en cours d'investigation.

L'œuvre de Charles Nicolle fut un peu oubliée des références de la médecine moderne, au nom du tournant scientifique représenté par la découverte de l'ADN par James Watson et Francis Crick en 1953. Tandis que nos connaissances progressent, les microbes poursuivent leur destin. Le rappel de la vision qu'a eu Charles Nicolle du destin des maladies infectieuses aura permis de mieux comprendre le génie évolutif local des microbes et d'aborder quelques hypothèses fondatrices de leur histoire scientifique. Les anciens disaient: «La peste? Tout un chacun connaît mais quand elle est là, personne ne la reconnaît.» Serait-ce encore le cas de la peste de demain? L'hypothèse de son association avec l'agent de la grippe rend plausible sa résurgence sous une forme pulmonaire plus adaptée au genre de vie moderne. Auquel cas la peste restera ce qu'elle a toujours été, une maladie de civilisation et il n'aura pas été inutile de rappeler ces histoires de maladies mortes ou dormantes.

71 Charles Nicolle, qui a voyagé en Europe, en Amérique, au Moyen Orient, projetait, en fin de vie, d'aller en Asie car il était persuadé que le typhus en était originaire, sans doute après avoir reçu une souche de Manchourie. La souche tunisienne était devenue le standard international; elle fut entretenue pendant 35 ans par Helena Sparrow et Abdelmajid Rahal, de «cobaye à cobaye», puis de «pou à pou», avant de rejoindre le musée de la science. 


\section{Bibliographie}

Achtman, Mark, et al., "Microevolution and history of the plague bacillus, Yersinia pestis", Proceedings of the Natural Academy of Sciences 51 (2004) 17837-17842

Aroua, Ahmed, Hygiène et prévention médicale chez Ibnou Sina (Avicenne) (Alger 1974)

Audoin-Rouzeau, Frédérique, «Le rat noir (Rattus rattus) et la peste dans l'Occident antique et médieval», Bulletin de la Société de Pathologie Exotique 92/5bis (1999) 422-426

- Les chemins de la peste: le rat, la puce et l'homme (Rennes 2003)

Ben Néfissa, Kmar, «La théorie de Charles Nicolle sur l'histoire naturelle des infections», Archives de l'Institut Pasteur de Tunis (2006) 1-4

Blanc, Georges/Marcel Baltazard, «Recherches sur le mode de transmission naturelle de la peste bubonique et septicémique», Archives de l'Institut Pasteur du Maroc 5 (1945) 173-234

Bloch, Edouard, La peste en Tunisie: aperçu historique et épidémiologique, thèse de doctorat en médecine (Paris 1929)

Burnet, Etienne, Microbes et toxines, avec une introduction d'Elie Metchnikoff (Paris 1911)

Chain, P. S. G., et al., "Insights into the evolution of Yersinia pestis through whole-genome comparison with Yersinia pseudotuberculosis", Proceedings of the National Academy of Sciences 58 (2004) 13826-13831

Conor, Marthe, «Une épidémie de peste en Afrique Mineure (1784-1788)», Archives de l'Institut Pasteur de Tunis (1911) 221-224

- «Invasions de sauterelles en Afrique Mineure (figures et textes inédits)», Archives de l'Institut Pasteur de Tunis (1914-1916) 148-156

Conrad, Lawrence I., "Arabic Plague Chronologies and Treatises: Social and Historical Factors in the Formation of a Literary Genre", Studia Islamica 54 (1981) 51-93

Conseil, Ernest, Le typhus exanthématique en Tunisie. Epidémie de 1906, thèse de doctorat de médecine (Paris 1907a)

- «Le typhus exanthématique en Tunisie», Archives de l'Institut Pasteur de Tunis (1907b) 145-154

- «Recherches expérimentales en Tunisie pendant l'année 1908», Archives de l'Institut Pasteur de Tunis (1909) 59-93

- «Le typhus exanthématique pendant l'année 1909-1910», Archives de l'Institut Pasteur de Tunis (1910) 19-42

- «Le typhus exanthématique pendant l'année 1910», Archives de l'Institut Pasteur de Tunis (1911a) 135-158

- «La peste pendant l'année 1910», Archives de l'Institut Pasteur de Tunis (1911b) 168-175

- /Paul Durand, «Très longue persistance ganglionnaire du bacille de la peste chez l'homme après guérison», Archives de l'Institut Pasteur de Tunis (1927) 92

- /Paul Durand, «La peste pulmonaire de Tunis, décembre 1929-Janvier 1930, Etudes épidémiologiques», Archives de l'Institut Pasteur de Tunis (1930) 229-266

Debré, Patrice, Louis Pasteur (Paris 1994)

Dinguizli, Béchir, «Des formes hygiéniques urgentes à introduire chez les populations musulmanes de Tunisie», La Dépêche Tunisienne, 24 mars 1930

Dols, Michael W., The Black Death in the Middle East (Princeton NJ 1977)

Duhamel, Georges, «Le message de Charles Nicolle», Revue de Paris, $1^{\text {er }}$ novembre 1935

Durand, Paul, «Sur un cas de peste chronique ayant duré 17 mois», Archives de l'Institut Pasteur de Tunis (1931) 77-82

Eager, J. M., The Present Pandemic of Plague (Washington 1908)

Gallagher, Nancy, Medicine and Power in Tunisia, 1780-1790 (Cambridge 1983)

Gobert, Ernest, «La peste dans le sud tunisien en 1920-1921», Archives de l'Institut Pasteur de Tunis (1921) 440-446

- «Le contrôle permanent de la peste en Tunisie», Archives de l'Institut Pasteur de Tunis (1932) 456-469

Huet, Maurice, Charles Nicolle, une biographie (1866-1936). Le pommier et l'olivier (Montpellier 1995)

Jorge, Ricardo, Le typhus exanthématique à Porto 1917-1919: communication faite au Comité international d'hygiène publique dans sa session d'Octobre 1919 (Lisbonne 1920)

- «Rongeurs et puces dans la conservation et la transmission de la peste», Office International d'Hygiène publique 1924-1927 (Paris 1928) 
Klein, Jean-Marie, et al., «Observations écologiques dans une zone enzootique de peste en Maurétanie», Cahiers de l'ORSTOM, Série Entomologie Médicale et Parasitologie 13 (1975) 29-39

Léon l'Africain, Description de l'Afrique, traduit de l'italien par A. Epaulard, 2 vols (Paris 1956)

Lot, Germaine, Charles Nicolle et la biologie conquérante (Paris 1961)

Marchika, Jean, La peste en Afrique septentrionale. Histoire de la peste en Algérie de 1363 à 1830 (Alger 1927)

Morgan, Thomas Hunt, Some Possible Bearings of Genetics on Pathology (Lancaster 1922)

Moulin, Anne Marie, «L'hygiène dans la ville: La médecine ottomane à l'heure pasteurienne (1887-1908)», dans: Paul Dumont et François Georgeon (éds), Les villes ottomanes à la fin de l'Empire (Paris 1992) 186-209

- «Charles Nicolle savant tunisien», Archives de l'Institut Pasteur de Tunis (1994) 335-370

- «Epidémies et contagions dans le monde arabe médiéval. A l'ombre d'Avicenne», dans: La médecine au temps des califes, Catalogue d'exposition, Paris, Institut du Monde Arabe (Paris 1996) 247-260

- «Richesse de l'œuvre médicale d'Ernest Gobert», dans: Coutumes et décors de Tunisie sous le regard d'Ernest Gustave Gobert (1901-1958) (Tunis 2007) 16-21

Netter, Arnold, «Tyhus exanthématique, Typhus récurrent», dans: Paul Brouardel/Augustin Gilbert, Nouveau traité de Médecine et de Thérapeutique (Paris 1905)

Nicolle, Charles, Cahiers de laboratoire: 26 cahiers manuscrits non numérotés, classés par année de 1904 à 1933, déposés dans l'armoire-musée Charles Nicolle de l'Institut Pasteur de Tunis

- Correspondance de Charles Nicolle avec Félix Mesnil et Emile Leredde, Services des Archives de l'Institut Pasteur de Paris (1904-1907)

- «Sur la nature des virus invisibles, origine microbienne des inframicrobes», Archives de l'Institut Pasteur de Tunis (1925) 105-120

- «Le vain débat de l'unité ou de la pluralité des agents pathogènes apparentés, en particulier des inframicrobes, que des caractères essentiels rapprochent», Archives de l'Institut Pasteur de Tunis (1935a) 409-419

- «Constitution de cultures pures et des virus en éléments vivants: association de virus variantes chez les inframicrobes», Archives de l'Institut Pasteur de Tunis (1935b) 139-178

- «Signification de la forme inapparente dans la naissance et le déclin des maladies infectieuses», Archives de l'Institut Pasteur de Tunis (1935c) 1-7

- Le Destin des Maladies Infectieuses (Paris 1937)

- /Charles Comte/Ernest Conseil, «Transmission expérimentale du typhus exanthématique par le pou du corps», Comptes-Rendus de l'Académie des Sciences (1909) 486

- /Ernest Gobert, «Considérations générales sur la peste pulmonaire et sur sa nature», Archives de l'Institut Pasteur de Tunis (1924) 212-225

- /Charles Lebailly, «Quelques notions expérimentales sur le virus de la grippe», ComptesRendus de l'Académie des Sciences (1918) 607-610

- /Helena Sparrow, «Sur une épizootie de pseudo-tuberculose du cobaye observée à Tunis. Son arrêt par la vaccination préventive», Archives de l'Institut Pasteur de Tunis (1928) 338-346

Panzac, Daniel, Quarantaines et lazarets. L'Europe et la peste d'Orient (Aix en Provence 1986)

Pelis, Kim, Pasteur's Imperial Missionary: Typhus and Tunisia (Rochester NY 2006)

Pollitzer, Robert, La peste, OMS, série monographies, ${ }^{\circ} 22$ (Genève 1954)

Proust, Lucien, La défense de l'Europe contre la peste (Paris 1897)

Raynaud, Lucien, «Le typhus exanthématique en Algérie», Revue d'Hygiène et de Police Sanitaire 35 (1923) 928-968

- «La peste en Algérie: l'épidémie de peste dans la région d'Alger. Cas de peste survenus dans la colonie de 1899 à 1924», Archives de l'Institut Pasteur d'Algérie (1924) 303-361

Remlinger, Paul, «La peste bubonique», Bulletin de l'hôpital civil français de Tunis (1899)

- «La peste au Maroc», Revue d'Hygiène et de Police Sanitaire 25 (1913) 11-24

Renaud, H. P. J., «La peste au Maroc, étude d'épidémiologie et de géographie médicale», Revue d'Hygiène et de Police Sanitaire 35 (1923) 193-215

Raynal, Jean/Alexandre Wassilieff, «Prophylaxie de la peste à Tunis. La station municipale de surveillance murine (Laboratoire du rat)», Archives de l'Institut Pasteur de Tunis (1932) 181-207 
Ristorcelli, A., «Les rongeurs sensibles à la peste dans la région du Nefzaoua», Archives de l'Institut Pasteur de Tunis (1938) 298-333

Rodhain, François, «Les fièvres récurrentes dans l'œuvre de Charles Nicolle», Médecine et Maladies infectieuses 19 (1989) 768-772

Rosenau, M. J., Viability of the Bacillus pestis (Washington 1901)

Saadaoui, Ahmed, "Al ta'à un: tableaux récapitulatifs des épidémies et sources d'études», Institut des Belles Lettres Arabes (IBLA) 175 (1995) 119-141

Salomon-Bayet, Claire, Pasteur et la révolution pasteurienne (Paris 1984)

Sebag, Paul, «La peste dans la Régence de Tunis aux XVII ${ }^{\text {ème }}$ et XVIII ${ }^{\text {ème }}$ siècles», Institut des Belles Lettres Arabes (IBLA) 109 (1965) 35-48

Speziale, Salvatore, Oltre la peste. Sanità, populazione e societâ in Tunisia e nel Maghreb (XVIII-XX secolo) (Cosenza 1997)

Stenseth, Nils Christian, et al., "Plague: Past, Présent, and Future", PLOS Medicine 5 (2008) e3, 0009-0013

Sublet, Jaqueline, «La peste aux rêts de la jurisprudence: le traité d'Ibn Hagar al' Asqualani sur la peste», Studia Islamica 33 (1971) 141-149

Wagner, J./Alexandre Wassilieff, «Tableau analytique pour la détermination des puces rencontrées en Algérie et en Tunisie», Archives de l'Institut Pasteur de Tunis (1933) 431-467

Wassilieff,Alexandre, «Rongeurs et puces en Tunisie et leur rôle dans la propagation de la peste», Archives de l'Institut Pasteur de Tunis (1932) 298-340

Zietz, Bjorn P./Hartmut Dunkelberg, "The History of the Plague and the Research on the Causative Agent, Yersinia pestis", International Journal of Hygiene and Environmental Health 207 (2004) 165-178 